\title{
Steroid hormone synthesis by the ovarian stroma surrounding epithelial ovarian tumors: a potential mechanism in ovarian tumorigenesis
}

\author{
Luis Z Blanco Jr ${ }^{1,5}$, Elisabetta Kuhn ${ }^{1}$, Jane C Morrison ${ }^{1}$, Asli Bahadirli-Talbott ${ }^{1}$, \\ Anne Smith-Sehdev ${ }^{2}$ and Robert J Kurman ${ }^{1,3,4}$ \\ ${ }^{1}$ Department of Pathology, The Johns Hopkins Medical Institutions, Baltimore, MD, USA; ${ }^{2}$ Department of \\ Pathology, Legacy Health Systems, Portland, OR, USA; ${ }^{3}$ Department of Gynecology and Obstetrics, The Johns \\ Hopkins Medical Institutions, Baltimore, MD, USA and ${ }^{4}$ Department of Oncology, The Johns Hopkins Medical \\ Institutions, Baltimore, MD, USA
}

\begin{abstract}
Epithelial ovarian tumors are responsive to steroid hormone stimulation and the ovarian stroma may have a direct role in this process. We evaluated immunohistochemical markers of sex-steroid differentiation and steroidogenesis (calretinin, inhibin, steroidogenic factor 1), steroid enzymes involved in hormone biosynthesis (CYP17, CYP19, HSD17ß1, AKR1C3), and hormone receptors (estrogen receptor, progesterone receptor, and androgen receptor) in 101 epithelial ovarian tumors and in normal structures implicated in ovarian carcinogenesis (ovarian surface epithelium and cortical inclusion cysts) in an attempt to elucidate this process. We hypothesized that ovarian stroma immediately adjacent to tumors express markers of sex-steroid differentiation and steroidogenesis and steroid enzymes whereas the epithelium contains corresponding hormone receptors. As the findings in seromucinous, endometrioid, and clear cell neoplasms, tumors closely associated with endometriosis, were very similar, these were combined into a group designated 'endometriosisrelated tumors.' Significantly increased expression of markers of sex-steroid differentiation and steroidogenesis was found in stroma immediately adjacent to endometriosis-related tumors $(P=0.003)$ and mucinous tumors (primary and metastatic mucinous tumors were combined because of similar findings) $(\boldsymbol{P}<0.0001)$ compared with more remote ovarian stroma. In addition, sex-steroid enzymes were increased in stroma adjacent to endometriosis-related tumors $(P=0.02)$ and mucinous tumors $(P=0.02)$ compared with more distant stroma. Steroid hormone receptors showed greater expression in epithelium compared with stroma in the endometriosisrelated tumors $(P=0.0009)$, low-grade serous tumors $(P<0.0001)$, and high-grade serous carcinoma $(P=0.0036)$. In contrast, there was greater expression in stroma compared with epithelium $(P<0.0001)$ in mucinous tumors, which may be due to the fact that they are not derived from müllerian epithelium. In conclusion, our findings strongly support the view that the stroma surrounding epithelial tumors in the ovary is activated to elaborate steroid hormones which may stimulate further neoplastic growth. The precise mechanisms by which this process might occur are complex and require further investigation.
\end{abstract}

Modern Pathology (2017) 30, 563-576; doi:10.1038/modpathol.2016.219; published online 6 January 2017

Correspondence: Dr LZ Blanco Jr, MD, Department of Pathology, Northwestern University Feinberg School of Medicine, Feinberg Pavilion 7-330, 251 East Huron Street, Chicago, IL 60611, USA. E-mail: luis.blanco@northwestern.edu

${ }^{5}$ Current address: Department of Pathology, Northwestern University Feinberg School of Medicine, Chicago, IL, USA.

Received 7 July 2016; revised 7 November 2016; accepted 8 November 2016; published online 6 January 2017
The traditional view regarding the origin and pathogenesis of epithelial ovarian carcinomas is that they develop from the ovarian surface epithelium or from cortical inclusion cysts through a process of invagination of ovarian surface epithelium. As carcinomas generally resemble the epithelium in the organs from which they are derived, the müllerian phenotype of epithelial ovarian cancers has been difficult to reconcile if their proposed origin is from the ovarian surface epithelium, which 
is essentially mesothelium. Accordingly, their müllerian phenotype has been explained by invoking metaplasia of the ovarian surface epithelium to müllerian-type epithelium which then undergoes malignant transformation. Recently, a less complex explanation for the müllerian phenotype of these tumors has been advanced by proposing that the precursor lesion of invasive high-grade serous carcinoma is an intraepithelial carcinoma in the fallopian tube, so-called serous tubal intraepithelial carcinoma that implants on the ovary. ${ }^{1-9}$ It has also been suggested that some serous tumors might develop from cortical inclusion cysts lined by tubal-type epithelium derived from the fallopian tube at the time of ovulation. ${ }^{1}$ Endometrioid and clear cell carcinomas are thought to develop from endometriosis which is generally thought to be derived from endometrial tissue by retrograde menstruation. $^{1-3}$ An obvious question is why do these tumors have a propensity to develop in the ovary rather than in the organ that is the site of the putative precursor lesion.

There is evidence that sex-steroid hormones have a role in ovarian carcinogenesis as demonstrated by studies showing that women on hormone replacement therapy have a significantly increased risk for ovarian cancer. ${ }^{10}$ In addition, cell culture studies have shown that hormones, including estradiol, progesterone, and androgens, may modulate the growth of epithelial ovarian cancer cells by stimulating cell proliferation and telomerase expression, inducing angiogenesis, and regulating metastasis through the PI3K/AKT pathway. ${ }^{11-16}$

In 1964, Scully described the presence of luteinized stromal cells immediately adjacent to primary and metastatic ovarian tumors and reported oxidative-enzyme activity in these cells, referring to them as enzymatically active stromal cells. He postulated that enzymatically active stromal cells stimulated growth of implanted epithelium by local synthesis of steroid hormones. ${ }^{17}$ With the availability of reagents that can identify enzymes involved in steroidogenesis, we undertook a morphologic and immunohistochemical analysis of the ovarian stroma from a variety of epithelial tumors, endometriotic cysts, and normal components of the ovary that have been proposed as possible precursors of ovarian cancer (ovarian surface epithelium and cortical inclusion cysts) to validate this hypothesis.

\section{Materials and methods}

\section{Case Selection}

A total of 101 ovarian tissues (neoplasms and normal tissue) and 11 normal fallopian tubes were retrieved from the pathology files of the Johns Hopkins Hospital (Baltimore, MD, USA) and Legacy Health Systems (Portland, OR, USA) from 1993 through 2014. All available slides and reports were reviewed.

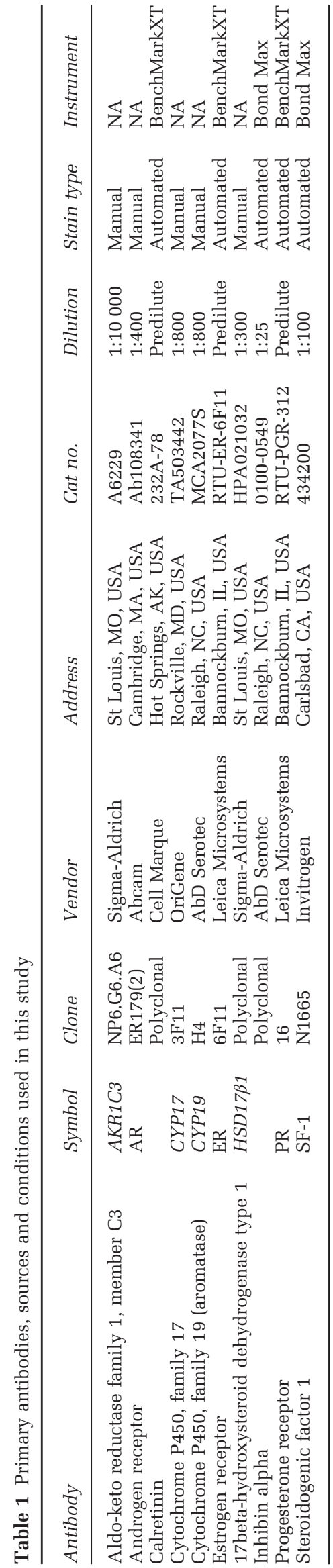


Table 2 Functions of targets of immunohistochemical stains (also see Figure 1)

\begin{tabular}{|c|c|c|}
\hline Target & Symbol & Function \\
\hline \multicolumn{3}{|c|}{ Markers of sex-cord differentiation/steroidogenesis } \\
\hline Calretinin & & Calcium-binding protein structurally related to inhibin \\
\hline Inhibin alpha & & $\begin{array}{l}\text { Peptide hormone that is a member of the transforming growth factor-beta } \\
\text { superfamily and has growth promoting activities; produced by ovarian granulose } \\
\text { cells to inhibit follicle-stimulating hormone }\end{array}$ \\
\hline Steroidogenic factor 1 & SF-1 & $\begin{array}{l}\text { Transcription factor that binds and activates the promoters of various } \\
\text { steroidogenic genes, including aromatase }\end{array}$ \\
\hline \multicolumn{3}{|l|}{ Markers of sex-steroid hormone receptors } \\
\hline Androgen receptor & AR & Receptor for androgen \\
\hline Estrogen receptor & ER & Receptor for estrogen \\
\hline Progesterone receptor & $\mathrm{PR}$ & Receptor for progesterone \\
\hline \multicolumn{3}{|l|}{ Markers of sex-steroid enzymes } \\
\hline $\begin{array}{l}\text { Aldo-keto reductase family } 1 \text {, member } \\
\text { C3 }\end{array}$ & AKR1C3 & $\begin{array}{l}\text { Also referred to as } 17 \text { beta-hydroxysteroid dehydrogenase type } 5 \text {; enzyme that } \\
\text { catalyzes the conversion between androstenedione and testosterone }\end{array}$ \\
\hline $\begin{array}{l}\text { Cytochrome P450, family } 17 \text { (17alpha } \\
\text { hydroxylase) }\end{array}$ & CYP17 & $\begin{array}{l}\text { Enzyme involved in the production of progestins, estrogens and androgens, } \\
\text { including catalyzing the cleavage of the C17-C20 bond of C21 steroids that is } \\
\text { essential for the biosynthesis of androgens }\end{array}$ \\
\hline $\begin{array}{l}\text { Cytochrome P450, family } 19 \\
\text { (aromatase) }\end{array}$ & CYP19 & $\begin{array}{l}\text { Enzyme that catalyzes the last steps of estrogen biosynthesis, converting } \\
\text { testosterone to estradiol }\end{array}$ \\
\hline $\begin{array}{l}\text { 17beta-hydroxysteroid dehydrogenase } \\
\text { type } 1\end{array}$ & $H S D 17 \beta 1$ & Enzyme that converts low activity estrone to the more potent estradiol \\
\hline
\end{tabular}

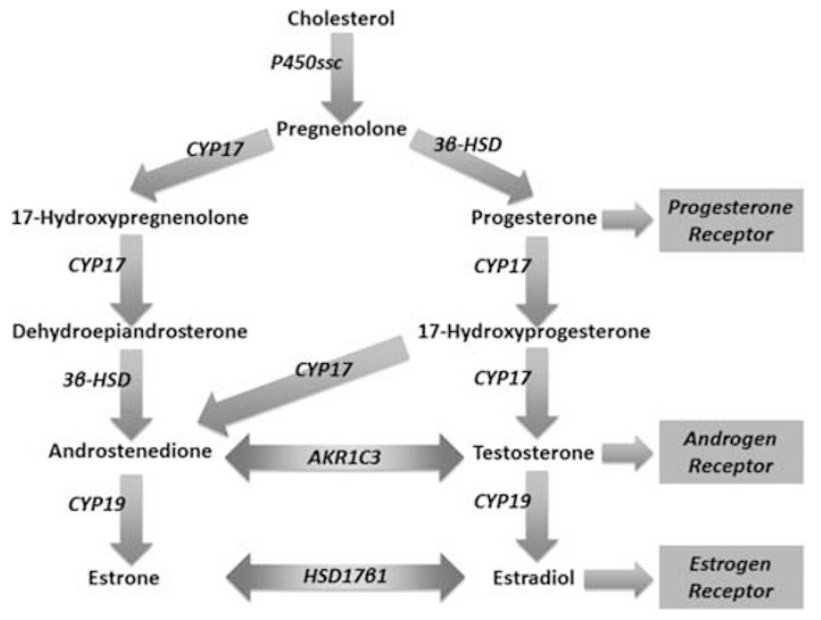

Figure 1 Steroidogenesis. Schematic representation of the steroidogenesis pathway of steroid hormone production and some of the major enzymes involved.

This study was approved by the Institutional Review Board of the Johns Hopkins Medical Institutions.

A total of 133 sections were evaluated from the 101 cases (one to three sections per case). These included 62 sections from malignant epithelial neoplasms (30 high-grade serous carcinomas, 6 low-grade serous carcinomas, 11 endometrioid carcinomas, 5 clear cell carcinomas, 1 mucinous carcinoma, 3 seromucinous carcinomas, and 6 metastatic carcinomas (3 colorectal and 3 low-grade appendiceal mucinous neoplasms), 33 atypical proliferative (borderline) tumors (19 serous, 6 seromucinous, and 8 mucinous, including 1 with intraepithelial carcinoma), 5 benign tumors ( 3 mucinous cystadenomas and 2 clear cell adenofibromas), 11 ovarian endometriosis/endometriotic cysts, 6 cortical inclusion cysts lined by tubal-type epithelium, 11 ovarian surface epithelium samples, and 5 normal ovaries. In addition, 10 sections of normal fallopian tube were evaluated.

\section{Immunohistochemistry}

The primary antibodies and conditions are shown in Table 1. Formalin-fixed, paraffin-embedded sections were immunostained using protocols described previously. ${ }^{18}$ The reagents used are all commercially available and listed in Table 1 and the tests were performed in accordance with the manufacturer's recommendations.

\section{Description of the Selected Antibodies}

Markers of sex-cord differentiation and steroidogenesis included calretinin, inhibin alpha, and steroidogenic factor 1 (SF-1). Markers of sex-steroid hormone receptors included estrogen receptor (ER), progesterone receptor (PR), and androgen receptor (AR). Markers of enzymes involved in sex steroidogenesis included CYP19 (cytochrome P450 family 19 or aromatase), CYP17 (cytochrome P450 family 17 or 17alpha-hydroxylase), HSD17 $\beta 1$ (17beta-hydroxysteroid dehydrogenase type 1), and AKR1C3 (aldo-keto reductase family 1 member C3 or 17betahydroxysteroid dehydrogenase type 5). Table 2 summarizes the selected immunohistochemical targets and their functions, while Figure 1 illustrates the specific functions of the sex-steroid enzymes in the steroidogenesis pathway. 


\section{Immunohistochemical Scoring}

Nuclear expression of SF-1, AR, ER, and PR, cytoplasmic expression of inhibin, and nuclear and/or cytoplasmic expression of calretinin, CYP19, CYP17, HSD17 $\beta 1$, and AKR1C3 were considered positive when $>5 \%$ of cells reacted. A semiquantitative scoring system was utilized, taking into account both the proportion of positive cells (5$25 \%+,>25-50 \%++,>50-75 \%+++,>75 \%++++)$ and the intensity of immunostaining [mild +(faint immunoreactivity at low power), moderate ++ (modest immunoreactivity at low power), or strong +++ (immunoreactivity easily appreciable at low power)]. ${ }^{19}$ The average proportion of positive cells and the average intensity were calculated for each marker. Immunoreactivity and intensity of staining was evaluated in the epithelium, stroma immediately adjacent to the epithelium (defined as ovarian stroma closely applied to the epithelium of the tumor, endometriosis or cortical inclusion cysts), and stroma that was distant from the epithelium (defined as ovarian stroma that was $\geq 10 \mathrm{~mm}$ away from the epithelium). Adjacent endometriosis was not present on sections evaluated for any of the tumors such as clear cell and endometrioid carcinomas and therefore only ovarian-type (and not endometrial-type) stroma was used for the analysis. To correlate the proportion of positive cells and intensity of immunostaining, the values were converted into composite immunohistochemical scores by multiplying the individual scores of proportion of positive cells by intensity. For example, a case with + ++ proportion of positive cells ( 3 points) and strong + ++ intensity ( 3 points) of immunostaining would have an immunohistochemical composite score of 9 $(3 \times 3)$. The average composite immunohistochemical score for each marker were then calculated and the differences of the means (epithelium vs adjacent stroma and adjacent vs distant stroma within each type of ovarian lesion, ie epithelium vs adjacent stroma in high-grade serous carcinoma) were statistically analyzed using the Student $t$-test (two-tailed). In addition, the correlation between specific enzyme expression in the adjacent stroma and the corresponding hormone receptors in the epithelium and stroma within each type of ovarian lesion (ie, $C Y P 17$ and $A K R 1 C 3$ with AR; CYP19 and HSD17 $\beta 1$ with ER) were evaluated using linear regression. All $P$ values $<0.05$ were considered statistically significant.

\section{Results}

\section{Morphology}

Ovarian stromal cells not surrounding follicles and stromal cells at a distance from the lesional epithelium were spindled cells with scant cytoplasm. In contrast, the stromal cells immediately adjacent to the lesional epithelium had variable morphology. Those associated with endometriosis/endometriotic cysts and benign, atypical proliferative (borderline) and malignant neoplasms were composed predominantly of lutein or theca-like cells (Figure 2). Luteinlike cells are polygonal cells with abundant eosinophilic or vacuolated cytoplasm and round nuclei, while theca-like cells are oval or plump spindledshaped cells that are densely cellular near the epithelium. $^{20}$ In some instances there was a mixture of the two types of cells. The differences in the expression of markers in adjacent and distant stromal cells could be a result of the stromal cell type composition or a transformation of the spindled cells into hormone producing lutein or theca-like cells. However in our study, as well as in a previous report ${ }^{20}$ there was no difference in the localization of the antigens despite the varying stromal morphology, therefore we did not distinguish them in our
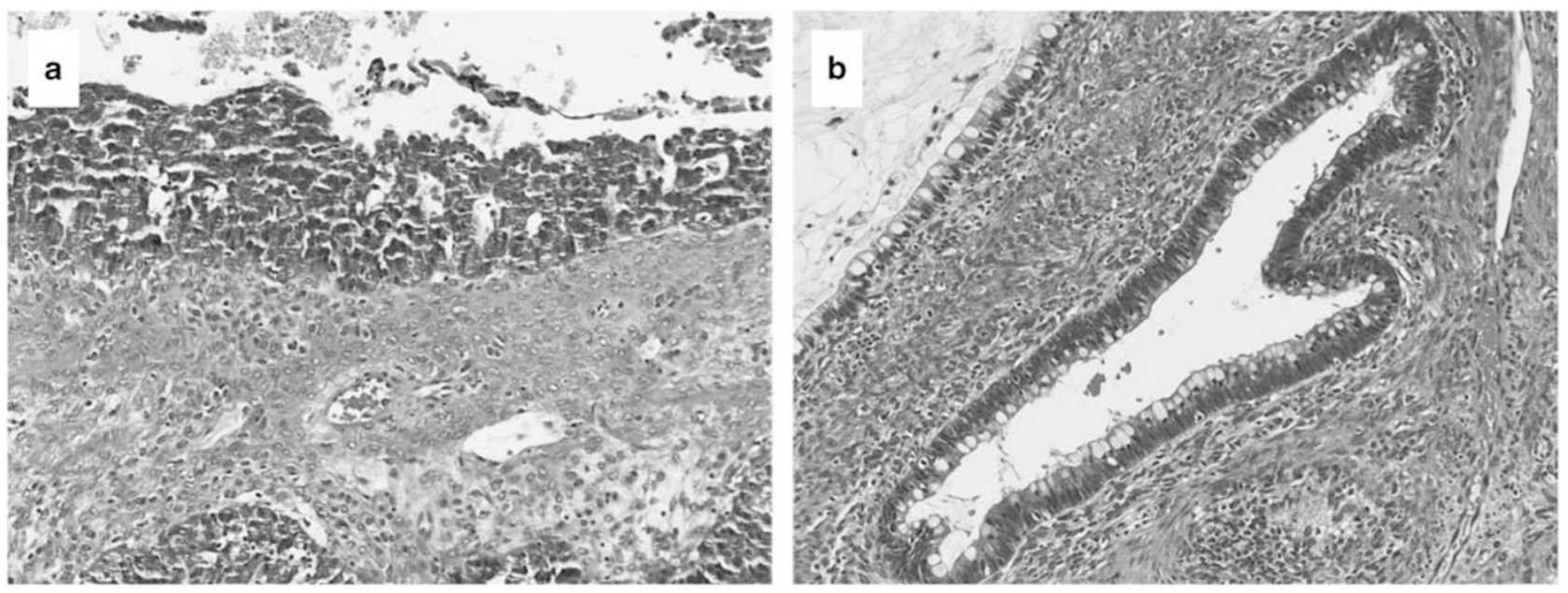

Figure 2 Representative hematoxylin and eosin-stained (H\&E) sections of (a) a high-grade serous carcinoma with lutein-like stromal cells adjacent to the malignant epithelium and (b) a mucinous carcinoma with theca-like stromal cells adjacent to the malignant epithelium. 


\begin{tabular}{|c|c|c|c|c|c|c|c|c|c|}
\hline & \multicolumn{4}{|c|}{ Adjacent stroma $a^{\mathrm{a}}$ composite score ${ }^{\mathrm{b}}$} & \multicolumn{4}{|c|}{ Distant stroma composite score $\mathrm{e}^{\mathrm{b}}$} & \multirow{2}{*}{$\begin{array}{l}\text { P-value of } \\
\text { adjacent vs } \\
\text { distant }^{\mathrm{d}}\end{array}$} \\
\hline & Calretinin & $\begin{array}{l}\text { Inhibin } \\
\text { alpha }\end{array}$ & $\begin{array}{c}\text { Steroidogenic factor } \\
1\end{array}$ & Total & Calretinin & $\begin{array}{l}\text { Inhibin } \\
\text { alpha }\end{array}$ & $\begin{array}{c}\text { Steroidogenic factor } \\
1\end{array}$ & Total & \\
\hline $\begin{array}{l}\text { Endometriosis-related tumors (atypical proliferative } \\
\text { seromucinous tumor, endometrioid carcinoma, clear } \\
\text { cell carcinoma, seromucinous carcinoma) } n=24\end{array}$ & 6.46 & 6.27 & 10.04 & 7.63 & 3.73 & 4.55 & 7.55 & 5.27 & 0.0038 \\
\hline $\begin{array}{l}\text { Low-grade serous tumors (atypical proliferative serous } \\
\text { tumor and low-grade serous carcinoma) } n=25\end{array}$ & 3.24 & 2.15 & 6.38 & 3.95 & 2.71 & 1.86 & 3.86 & 2.81 & 0.1160 \\
\hline High-grade serous carcinoma $n=30$ & 4.29 & 4.18 & 3.61 & 4.02 & 2.3 & 5.7 & 6.4 & 4.8 & 0.2403 \\
\hline $\begin{array}{l}\text { Mucinous tumors (atypical proliferative mucinous } \\
\text { tumor, primary and metastatic mucinous carcinoma) } \\
n=15\end{array}$ & 8.5 & 9.86 & 10.21 & 9.52 & 4.36 & 4.55 & 6.45 & 5.12 & $<0.0001$ \\
\hline
\end{tabular}

${ }^{\mathrm{a} S}$ Stromal cells immediately adjacent to epithelium. ${ }^{\mathrm{b}}$ Average composite score (proportion $\times$ intensity). ${ }^{\mathrm{C}}$ Stromal cells not immediately adjacent to epithelium (not present in all sections examined)

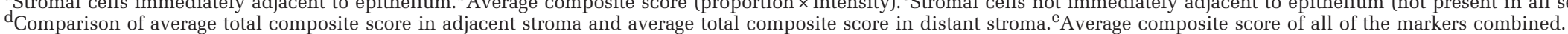

Table 4 Immunohistochemical results of markers of sex-steroid hormone receptors in epithelium and adjacent ovarian stroma

\begin{tabular}{|c|c|c|c|c|c|c|c|c|c|}
\hline \multirow{2}{*}{ Tumor type } & \multicolumn{4}{|c|}{ Epithelium composite score ${ }^{\mathrm{a}}$} & \multicolumn{4}{|c|}{ Adjacent stroma ${ }^{\mathrm{b}}$ composite score $\mathrm{a}^{\mathrm{a}}$} & \multirow{2}{*}{$\begin{array}{l}\mathrm{P} \text {-value of } \\
\text { epithelium vs } \\
\text { adjacent }\end{array}$} \\
\hline & $\begin{array}{l}\text { Estrogen } \\
\text { receptor }\end{array}$ & $\begin{array}{l}\text { Progesterone } \\
\text { receptor }\end{array}$ & $\begin{array}{l}\text { Androgen } \\
\text { receptor }\end{array}$ & Total $^{\mathrm{d}}$ & $\begin{array}{l}\text { Estrogen } \\
\text { receptor }\end{array}$ & $\begin{array}{l}\text { Progesterone } \\
\text { receptor }\end{array}$ & $\begin{array}{l}\text { Androgen } \\
\text { receptor }\end{array}$ & Total & \\
\hline $\begin{array}{l}\text { Endometriosis-related tumors (atypical } \\
\text { proliferative seromucinous tumor, } \\
\text { endometrioid carcinoma, clear cell } \\
\text { carcinoma, seromucinous carcinoma) } n=24\end{array}$ & 8.55 & 7.64 & 3.1 & 7.17 & 3.36 & 4.18 & 6.7 & 4.31 & 0.0009 \\
\hline $\begin{array}{l}\text { Low-grade serous tumors (atypical } \\
\text { proliferative serous tumor and low-grade } \\
\text { serous carcinoma) } n=25\end{array}$ & 5.65 & 7.81 & 4.85 & 6.17 & 0.71 & 1.63 & 3.92 & 1.93 & $<0.0001$ \\
\hline High-grade serous carcinoma $n=30$ & 7.09 & 3.22 & 7.28 & 5.97 & 1.78 & 3.78 & 5.21 & 3.72 & 0.0036 \\
\hline $\begin{array}{l}\text { Mucinous tumors (atypical proliferative } \\
\text { mucinous tumor, primary and metastatic } \\
\text { mucinous carcinoma) } n=15\end{array}$ & 0.14 & 0.86 & 0.5 & 0.5 & 3.57 & 5.07 & 6.33 & 4.93 & $<0.0001$ \\
\hline
\end{tabular}

${ }^{\mathrm{a}}$ Average composite score (proportion $\times$ intensity). ${ }^{\mathrm{b}}$ Stromal cells immediately adjacent to epithelium. ${ }^{\mathrm{c}}$ Comparison of average total composite score in epithelium and average total composite score in adjacent stroma using $t$-test. ${ }^{d}$ Average composite score of all of the markers combined. 
analysis. Metastatic tumors and some malignant ovarian neoplasms had desmoplastic stroma composed of fibroblastic-like spindled cells with pale cytoplasm. Desmoplastic stroma was distinguished from luteinized stroma and was negative for all markers tested.

\section{Immunohistochemical Findings}

Preliminary analysis revealed some correlation between the markers in the ovarian stroma and in the epithelium depending on the specific ovarian lesions and tumors. Given these findings and based on known and reported clinicopathologic, immunohistochemical, and molecular data on the general groups of ovarian epithelial tumors and ovarian carcinogenesis which has been recently summarized, ${ }^{21}$ we grouped the tumors and performed statistical analysis in four categories as follows: (1) endometriosis-related tumors (atypical proliferative (borderline) seromucinous tumors, ${ }^{22-26}$ clear cell carcinoma, endometrioid carcinoma and seromucinous carcinoma), (2) low-grade serous tumors (atypical proliferative (borderline) serous tumors and low-grade serous carcinoma) (3) highgrade serous carcinoma, and (4) intestinal-type mucinous tumors (atypical proliferative (borderline) mucinous tumors, primary, and metastatic mucinous carcinoma). Primary and metastatic mucinous carcinomas, classified accordingly based on the criteria in the 2014 WHO Classification of Tumours of the Female Reproductive Organs, ${ }^{27}$ exhibited similar immunohistochemical profiles and because of the small number of cases were analyzed together in one group. A summary of the results indicating the immunohistochemical composite scores for the various markers are presented in Tables 3, 4 and 5. Representative images are shown in Figures 3, 4 and 5.

\section{Markers of Sex-Steroid Differentiation and Steroidogenesis (Calretinin, Inhibin, and Steroidogenic Factor 1)}

There was a statistically significant difference in the composite score for calretinin, inhibin and SF-1 together in the adjacent vs the distant stroma in endometriosis-related tumors $(P=0.0038)$ and

Table 5 Immunohistochemical results of markers of sex-steroid enzymes in ovarian stroma

\begin{tabular}{|c|c|c|c|c|c|c|c|c|c|c|c|}
\hline \multirow{2}{*}{ Tumor type } & \multicolumn{5}{|c|}{ Adjacent stroma ${ }^{\mathrm{a}}$ composite score ${ }^{\mathrm{b}}$} & \multicolumn{5}{|c|}{ Distant stroma ${ }^{\mathrm{C}}$ composite score ${ }^{\mathrm{b}}$} & \multirow{2}{*}{$\begin{array}{l}\text { P-value of adjacent } \\
\text { vs distant }\end{array}$} \\
\hline & AKR1C3 & CYP17 & CYP19 & $H S D 17 \beta 1$ & Total $^{\mathrm{e}}$ & AKR1C3 & CYP17 & CYP19 & $H S D 17 \beta 1$ & Total & \\
\hline $\begin{array}{l}\text { Endometriosis-related } \\
\text { tumors (atypical } \\
\text { proliferative seromucinous } \\
\text { tumor, endometrioid } \\
\text { carcinoma, clear cell } \\
\text { carcinoma, seromucinous } \\
\text { carcinoma) } n=24\end{array}$ & 7.88 & 6.5 & 1.8 & 0.22 & 4 & 3.75 & 0.5 & 0 & 0 & 1.13 & 0.0203 \\
\hline $\begin{array}{l}\text { Low-grade serous tumors } \\
\text { (atypical proliferative } \\
\text { serous tumor and low-grade } \\
\text { serous carcinoma) } n=25\end{array}$ & 6 & 0.23 & 0.67 & 0.33 & 1.6 & 5.25 & 0 & 0 & 0 & 1.08 & 0.4251 \\
\hline $\begin{array}{l}\text { High-grade serous } \\
\text { carcinoma } n=30\end{array}$ & 6.25 & 1.72 & 1.31 & 0.96 & 2.54 & 8.79 & 0.52 & 0.52 & 1 & 2.56 & 0.9769 \\
\hline $\begin{array}{l}\text { Mucinous tumors (atypical } \\
\text { proliferative mucinous } \\
\text { tumor, primary and } \\
\text { metastatic mucinous } \\
\text { carcinoma) } n=15\end{array}$ & 8.27 & 7.92 & 1.1 & 1 & 4.73 & 6.44 & 1.44 & 0.75 & 0.78 & 2.4 & 0.0167 \\
\hline
\end{tabular}

${ }^{\mathrm{a}}$ Stromal cells immediately adjacent to epithelium. ${ }^{\mathrm{b}}$ Average composite score (proportion $\times$ intensity). ${ }^{\mathrm{c}}$ Stromal cells not immediately adjacent to epithelium (not present in all sections examined). ${ }^{\mathrm{d}}$ Comparison of average total composite score in adjacent stroma and average total composite score in distant stroma using $t$-test. ${ }^{\mathrm{e}}$ Average composite score of all of the markers combined.

Figure 3 Representative sections of endometriosis-related tumors with column a demonstrating an endometrioid carcinoma including a hematoxylin and eosin-stained (H\&E) section. Strong nuclear immunoreactivity for progesterone receptor (PR) is seen in the malignant epithelium (similar expression of estrogen receptor (ER) and androgen receptor (AR) were also observed in this case; not illustrated). Sexsteroid enzymes CYP17 and CYP19 are observed in the stroma immediately adjacent to the epithelium. Column b shows a clear cell carcinoma including including a H\&E-stained section. Nuclear immunoreactivity for steroidogenic factor 1 (SF-1) and cytoplasmic and nuclear immunoreactivity for calretinin are present in the stromal cells. Sex-steroid enzyme CYP17 is present in the stroma immediately adjacent to the epithelium. 
a
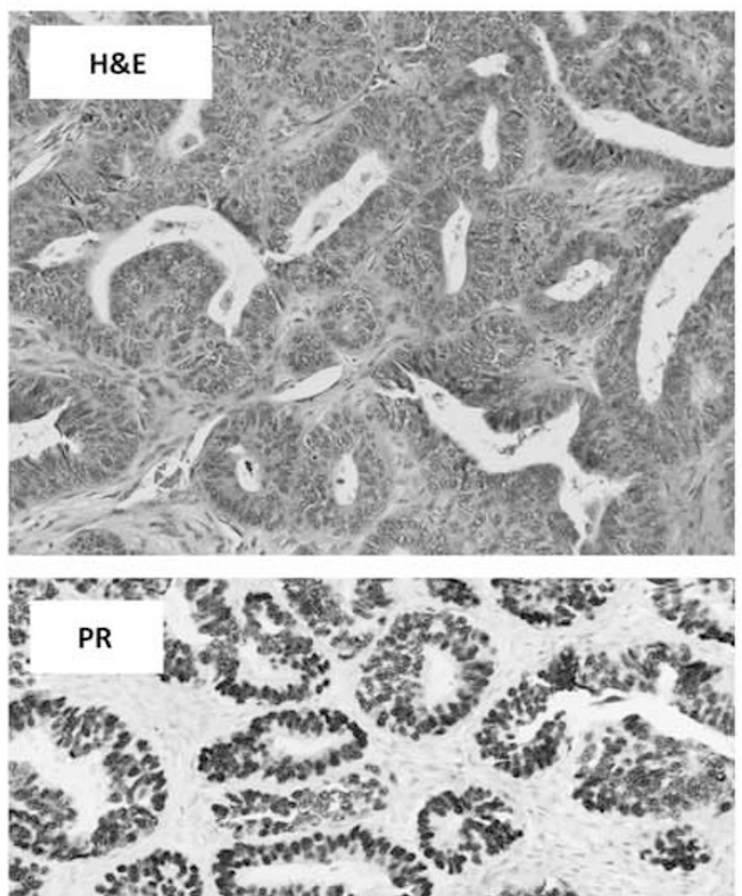

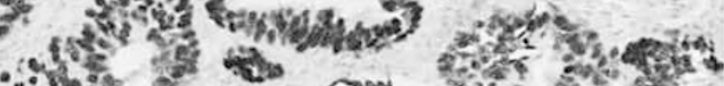

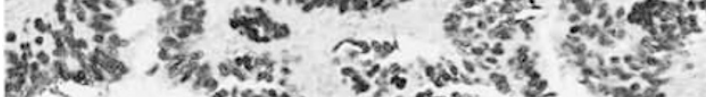
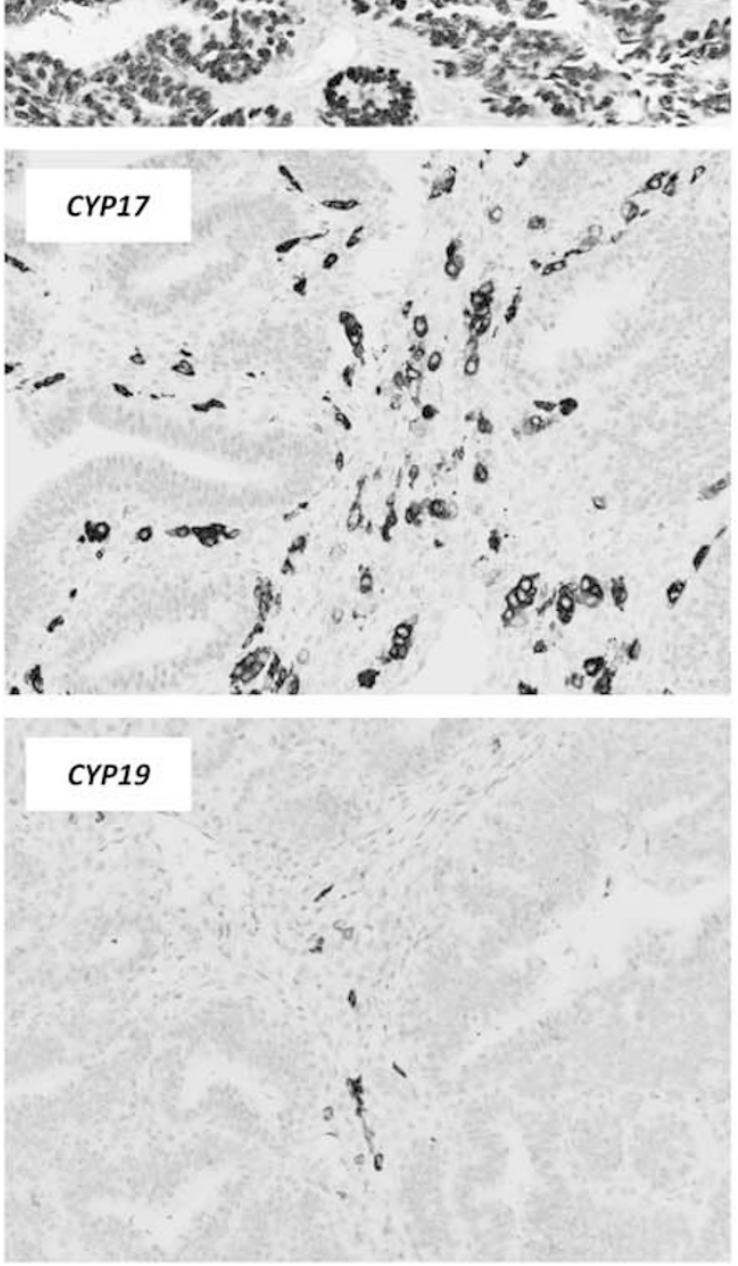

b
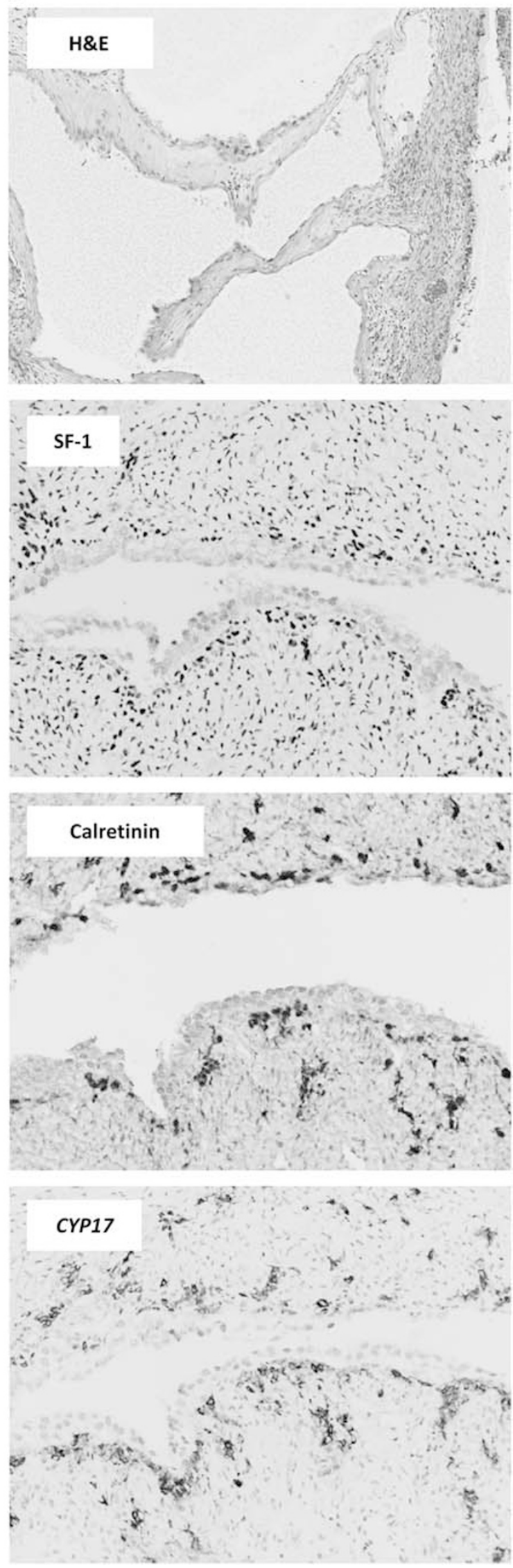
a
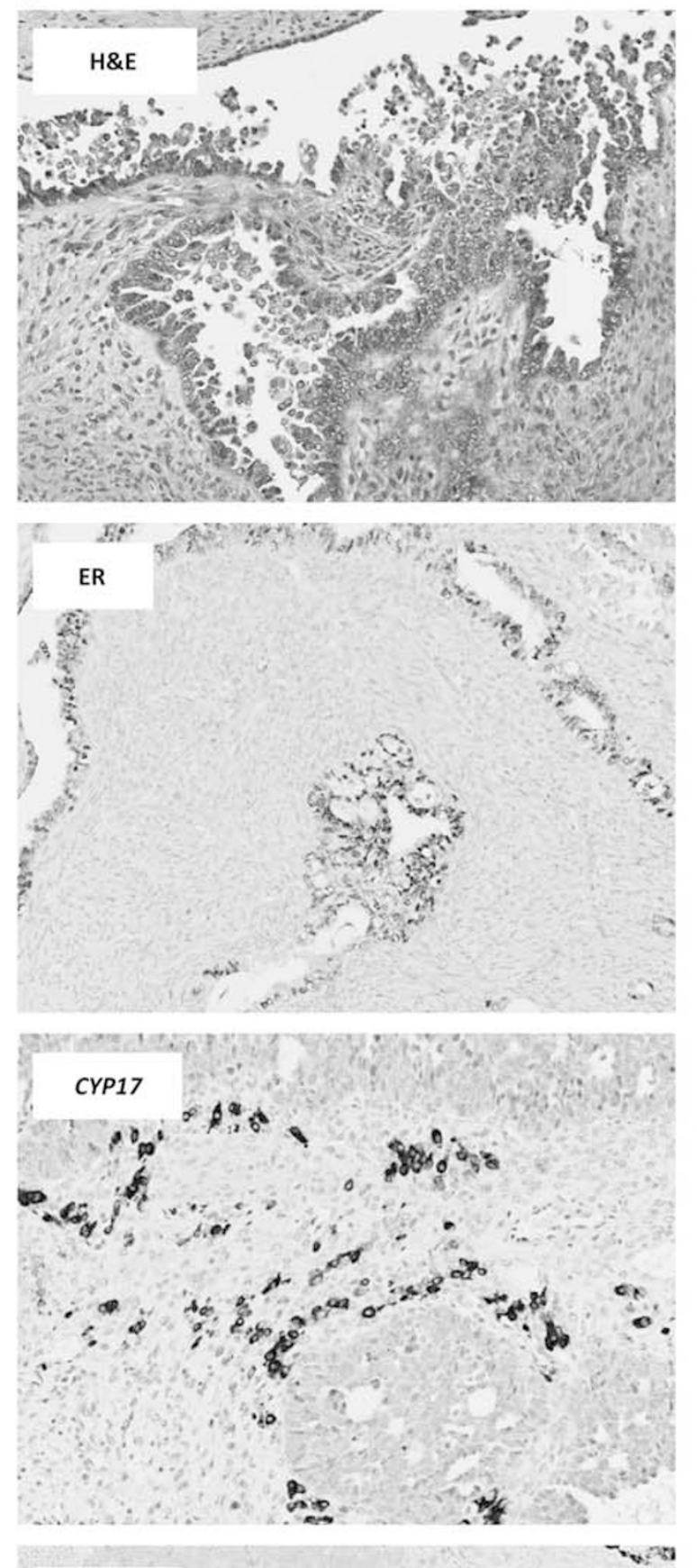

b
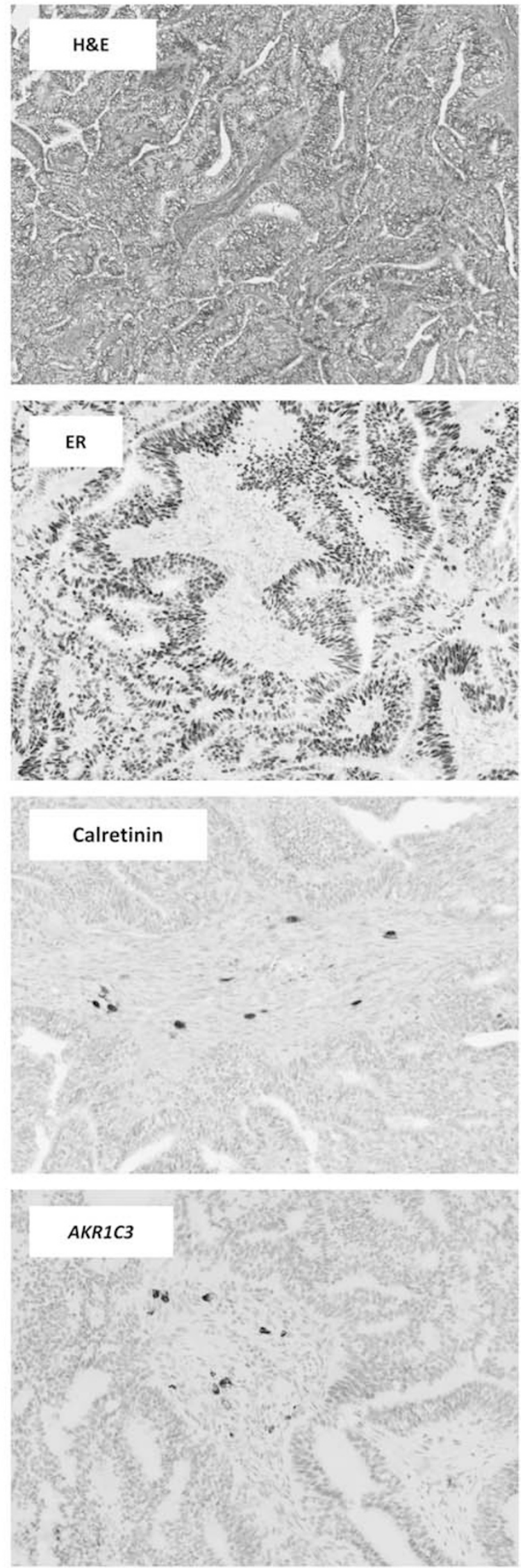
mucinous tumors $(P<0.0001)$ (Table 3$)$. This was also the case when individual markers were compared.

In contrast, for low-grade serous tumors and highgrade serous carcinoma, there was no statistically significant difference in the adjacent compared with the distant stroma. However, in high-grade serous carcinoma, calretinin was significantly higher in the adjacent $v s$ the distant stroma $(P=0.0289)$ while SF-1 was higher in the distant vs the adjacent stroma $(P=0.0279)$. No differences were observed in the individual markers in low-grade serous tumors.

\section{Markers of Sex-Steroid Enzymes (CYP17, CYP19, $H S D 17 \beta 1$, and $A K R 1 C 3)$}

There was significantly increased expression of these combined markers in the adjacent compared with the distant stroma for the endometriosis-related tumors $(P=0.0203)$ and the mucinous tumors $(P=0.0167)$ (Table 4). More specifically, CYP17, an enzyme involved in the biosynthesis of androgens, was significantly higher in the adjacent compared with the distant stroma in endometriosis-related tumors $(P=0.0078)$ and mucinous tumors $(P=0.0010)$, but $A K R 1 C 3$, another enzyme involved in androgen biosynthesis, was not significantly increased in the adjacent compared with the distant stroma. Interestingly it was also expressed in the epithelium of the mucinous tumors. Expression of CYP19 (aromatase), which is involved in the conversion of testosterone to estradiol, and $H S D 17 \beta 1$, an enzyme that converts low activity estrone to the more potent estradiol, was not statistically different between the adjacent and distant stroma. There was also no significant difference in the expression of these markers in the stroma associated with lowgrade serous tumors and high-grade serous carcinoma.

\section{Markers of Sex-Steroid Hormone Receptors (Androgen Receptor, Estrogen Receptor, and Progesterone Receptor)}

Expression of ER was significantly higher in the epithelium compared with the adjacent stroma of endometriosis-related tumors $(P=0.00001)$, lowgrade serous tumors $(P<0.0001)$, and high-grade serous carcinoma $(P=0.0036)$ (Table 5). Similarly, there was a statistically significant increased expression of ER in the epitheium compared with the adjacent stroma of low-grade serous tumors
$(P=0.0003)$ and high-grade serous carcinoma $(P<0.0001)$ and $\mathrm{PR}$ in the epithelium compared with the adjacent stroma of endometriosis-related tumors $(P=0.0104)$, whereas there was significantly decreased expression of ER $(P<0.0001)$ and PR $(P=0.0108)$ in the epithelium compared with the adjacent stroma of mucinous tumors. In contrast, AR was significantly decreased in the epithelium compared with the adjacent stroma of endometriosisrelated tumors and mucinous tumors.

\section{Comparison of Sex-Steroid Enzyme Expression in Stroma Immediately Adjacent to Epithelium and Hormone Receptors in the Corresponding Epithelium and in the Stroma Immediately Adjacent to Epithelium}

Overall, 27 cases that expressed CYP17, which is essential for the biosynthesis of androgens, also had $\mathrm{AR}$ available for review. In endometriosis-related tumors, greater CYP17 expression correlated with greater AR expression within the adjacent stroma in endometriosis-related tumors $\left(r^{2}=0.8696\right.$, $P=0.0208, n=5)$ and mucinous tumors $\left(r^{2}=0.5366\right.$, $P=0.0104, n=11)$. Interestingly, in high-grade serous carcinoma $\left(r^{2}=0.6630, P=0.0486, n=6\right)$, a statistically significant inverse relationship was observed with greater $C Y P 17$ expression in adjacent stroma correlating with less AR expression in the epithelium, suggesting a potential interplay between the enzyme and its corresponding hormone receptor. These findings suggest that these enzymes may be producing hormones that support the stroma itself in an autocrine fashion but not necessarily with the epithelium.

A total of 44 cases with AKR1C3 expression also had corresponding AR for analysis. Interestingly, in low-grade serous tumors $\left(r^{2}=0.5490, P=0.0567\right.$, $n=7)$ there was a trend for increased AKR1C3 expression (an enzyme involved in androgen biosynthesis) in adjacent stroma with greater AR in epithelium, while in high-grade serous carcinoma, $\left(r^{2}=0.2509, \quad P=0.0176, \quad n=22\right), \quad$ greater AKR1C3 expression significantly correlated with greater AR expression within the adjacent stroma itself. These findings also support a potential function of the stroma of producing androgens that stimulate the stroma as well as the epithelium.

A total of 15 cases with CYP19, which is essential for the biosynthesis of estrogens, also had corresponding ER for analysis. In high-grade serous carcinoma, greater CYP19 significantly correlated with greater ER expression within the adjacent

Figure 4 Representative sections of serous tumors with column a showing a high-grade serous carcinoma including a hematoxylin and eosin-stained (H\&E) section. Strong nuclear immunoreactivity for estrogen receptor (ER) is seen in the malignant epithelium. Sex-steroid enzymes CYP17 and CYP19 are observed in the stroma immediately adjacent to the epithelium. Column b represents a low-grade serous carcinoma including a H\&E-stained section. Strong immunoreactivity for ER is seen in the epithelium, while focal cytoplasmic and nuclear immunoreactivity for calretinin is present in the stromal cells. Sex-steroid enzyme AKR1C3 is present in the stroma immediately adjacent to the epithelium. 
a
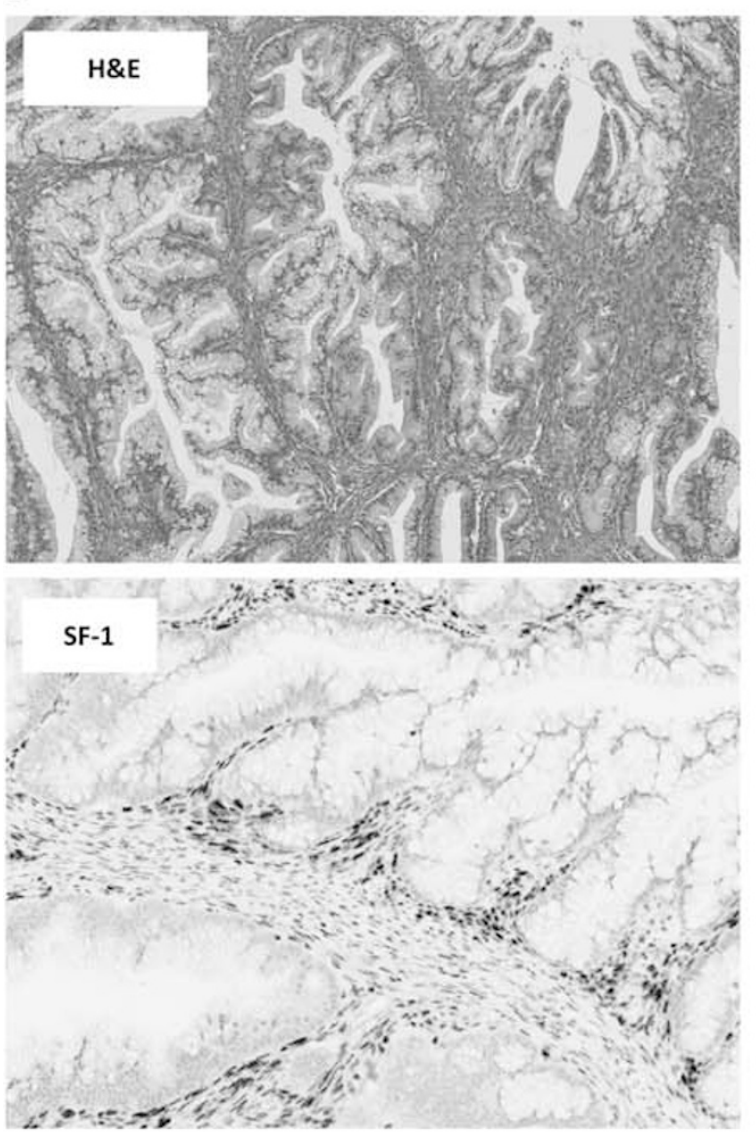

b
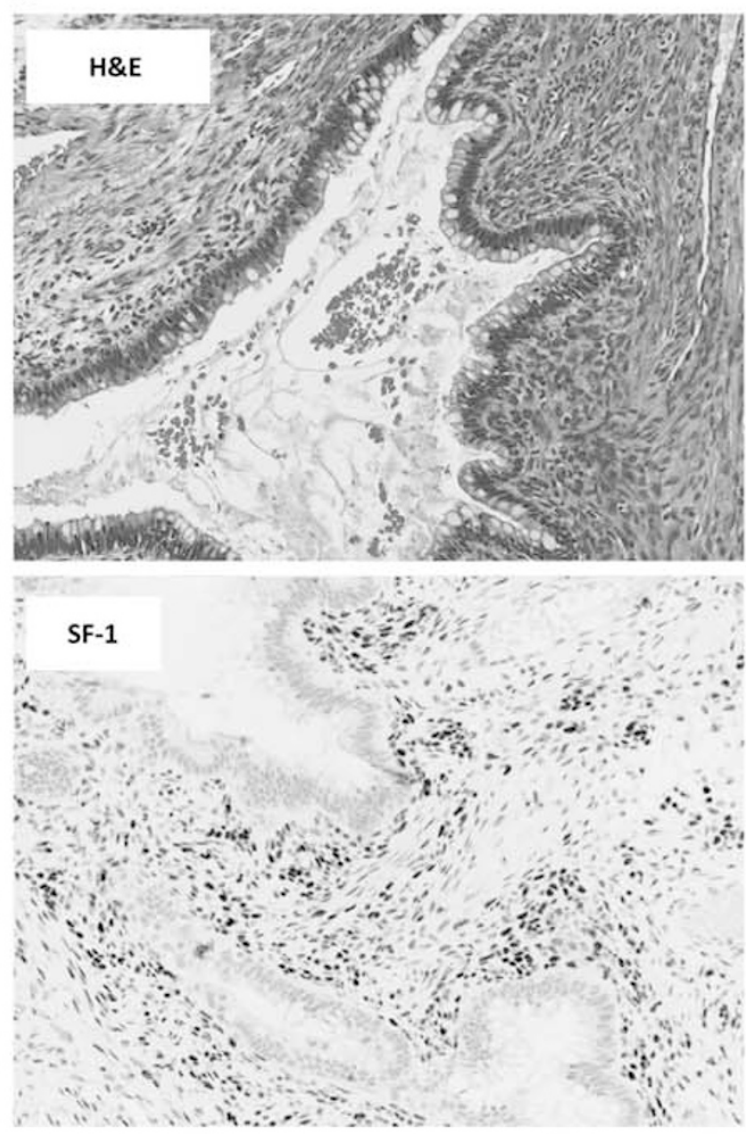
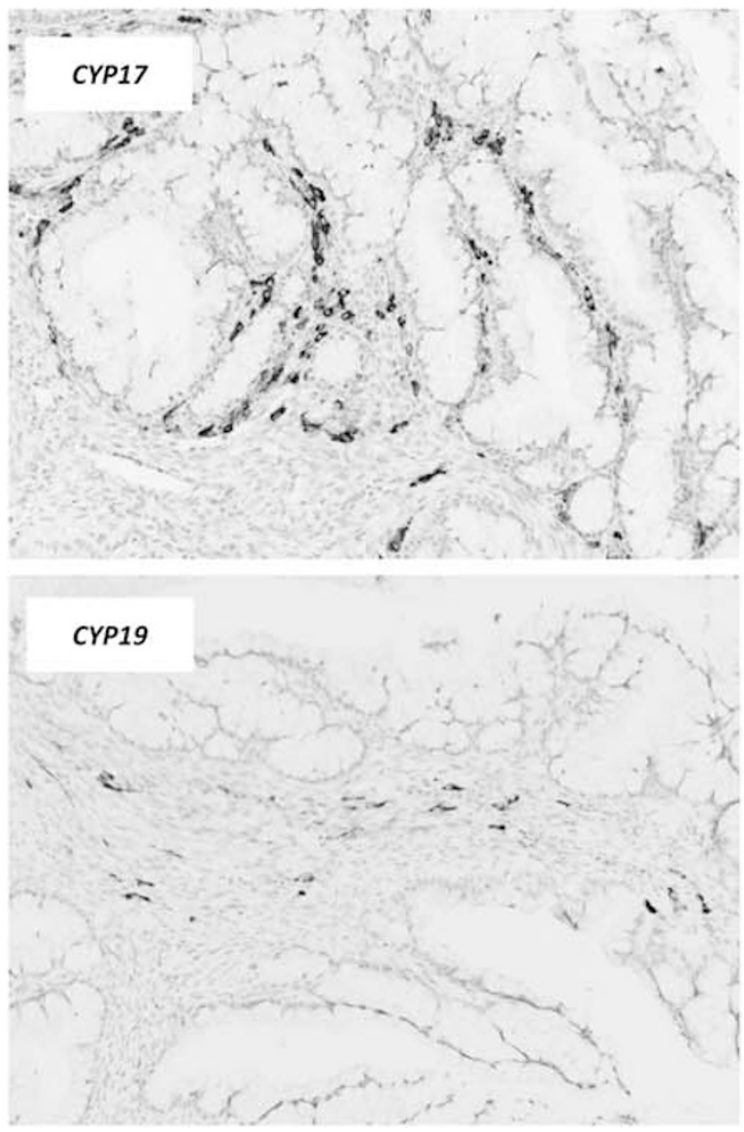
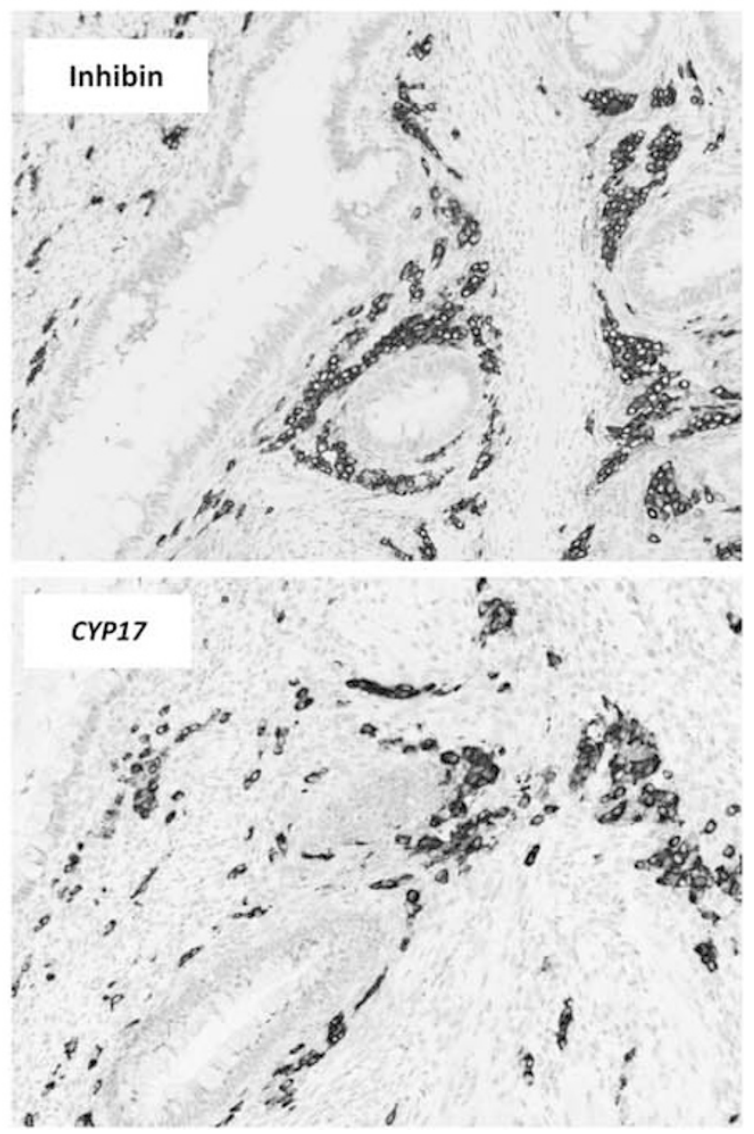
stroma itself $\left(r^{2}=0.7921, P=0.0175, n=6\right)$, again suggesting a potential autocrine function in the adjacent stroma.

No other significant correlations were observed.

\section{Expression of Sex-Steroid Markers and Enzymes and Hormone Receptors in Cortical Inclusion Cysts, Ovarian Surface Epithelium, Endometriosis, and Fallopian Tube}

Expression of calretinin, inhibin and SF-1 was significantly less in the adjacent compared with the distant stroma for cortical inclusion cysts
$(P=0.0479)$ and ovarian surface epithelium $(P=0.0002)$. The epithelium in cortical inclusion cysts had significantly greater hormone receptor (AR, ER, and PR) expression than the adjacent stroma $(P=0.0262)$ but expression of sex-steroid enzymes in the adjacent stroma was low and did not differ from that of the distant stroma. Statistically significant differences were not observed in ovarian surface epithelium with regards to these markers.

There was a trend of greater expression of sexsteroid enzymes in the adjacent compared with the distant stroma in endometriosis $(P=0.0586)$ but
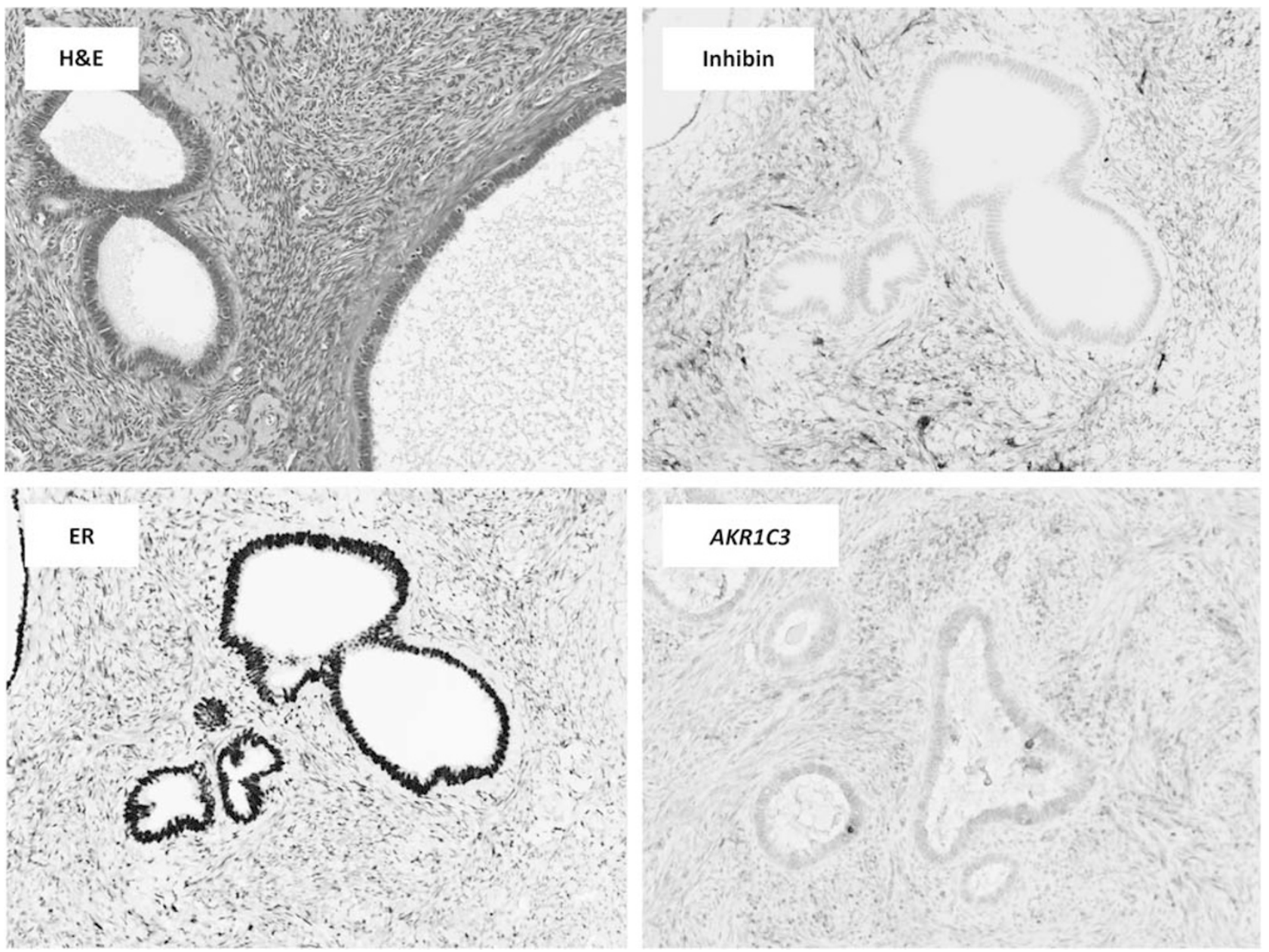

Figure 6 Representative sections of a cortical inclusion cyst with activated stroma including a hematoxylin and eosin-stained (H\&E) section. Cytoplasmic immunoreactivity for inhibin is present in the stromal cells. Sex-steroid enzyme AKR1C3 is focally present in the stroma immediately adjacent to the epithelium.

Figure 5 Representative sections of mucinous tumors with column A demonstrating a mucinous carcinoma including a hematoxylin and eosin-stained (H\&E) section. Immunoreactivity for steroidogenic factor 1 (SF-1) is present in the stromal cells, while strong immunoreactivity for progesterone receptor (PR) and androgen receptor (AR) is seen in the malignant epithelium. Sex-steroid enzymes CYP17 and CYP19 are observed in the stroma immediately adjacent to the epithelium. Column B shows an atypical proliferative (borderline) mucinous tumor including a H\&E-stained section. Nuclear immunoreactivity for SF-1 and cytoplasmic immunoreactivity for inhibin are present in the stromal cells. Sex-steroid enzyme CYP17 is present in the stroma immediately adjacent to the epithelium. 
there were no significant differences in sex-steroid marker and hormone receptor expression in these lesions.

The majority of both fallopian tube epithelium and adjacent stroma expressed ER, PR, AR, and AKR1C3, while in one-third of the cases adjacent stroma was immunoreactive for calretinin. The other markers were not expressed in either the epithelium or stroma. Overall, no significant findings were observed in the fallopian tubes.

\section{Discussion}

The demonstration of enzymes involved in steroidogenesis in the stroma immediately adjacent to ovarian tumors and the presence of corresponding hormone receptors in the epithelium of some of these tumors confirms previous reports ${ }^{20,28,29}$ and provides compelling evidence that the epithelium of ovarian tumors activates the surrounding stroma to produce steroid hormones, and, that these hormones can potentially stimulate the growth of the tumors. In contrast to the typical ovarian stroma, but similar to the theca interna surrounding developing follicles, the ovarian stroma immediately adjacent to ovarian neoplasms is composed of lutein-like or theca-like cells which are particularly prominent in mucinous tumors, both primary and metastatic (Figure 2b). However, the overall number of mucinous tumors in this series is small and therefore we are unable to draw firm conclusions for this tumor type. Further, given that a majority of our cases were referred cases, complete clinical information including menstrual status were not available and could not be correlated with our findings.

SF-1 is a nuclear transcription factor that is thought to regulate the gene for the alpha subunit of inhibin and plays an important role in the development of the gonads and adrenal glands, sexual differentiation, reproduction, and metabolism. ${ }^{30-33}$ In endometriosis-related and mucinous tumors, SF-1 was expressed significantly more in the adjacent compared with the distant stroma. Inhibin, a member of the transforming growth factor superfamily with growth promoting activities ${ }^{34}$ has a paracrine action in the ovary and regulates luteinizing hormone-induced androgen production by theca cells. ${ }^{35,36}$ We found that inhibin was significantly increased in the stroma adjacent to mucinous tumors. Calretinin, a $29-\mathrm{kD}$ calcium-binding protein structurally related to inhibin, ${ }^{37}$ was also elevated in the stroma adjacent to endometriosis-related, mucinous tumors, and high-grade serous carcinoma.

The significantly increased expression of enzymes involved in the synthesis of sex-steroid hormones in the stroma immediately adjacent to most of the tumors, especially endometriosis-related and mucinous tumors, strongly suggests that locally produced steroid hormones may support the growth and proliferation of these neoplasms. Of the four enzymes evaluated, CYP17, an enzyme that catalyzes the C17-C20 bond side chain cleavage of C21 steroids and is therefore essential for the biosynthesis of androgens, ${ }^{38}$ was the most significantly expressed enzyme in stroma of the various tumors, particularly in endometriosis-related and mucinous tumors. More specifically, increased CYP17 correlated with increased AR expression in the stroma itself. Curiously, increased expression of CYP17 in the stroma correlated with decreased expression of AR in the corresponding epithelium of high-grade serous carcinoma. These findings suggest an intricate interplay between the neoplasms and the ovarian stroma, including a possible negative feedback mechanism between the hormones in the stroma and the receptors in the epithelium.

In attempting to understand the possible role of locally synthesized steroid hormones and tumorigenesis, the conversion of androgens to estrogen also needs to be considered. A recent study suggests that significant amounts of estrogen are likely to be the result of peripheral aromatization of androgens ${ }^{20}$ and although ovarian stromal cells express enzymes supporting their capacity to convert androgens to estrogens, ${ }^{28,29}$ it remains to be seen whether this occurs locally. In our study no correlation was observed between CYP17 in the stroma and ER in the epithelium of any of the tumors. Similarly, $A K R 1 C 3$, an enzyme that catalyzes the reversible conversion of the 17-keto and $17 \beta$-hydroxy groups in androgens and estrogens, including the conversion of androstenedione to testosterone,${ }^{38,39}$ was consistently immunoreactive in the ovarian stroma of many tumors in our study, but there was no significant correlation between AKR1C3 expression and $\mathrm{AR}$ expression in the neoplastic epithelium. Conversely, increased AKR1C3 correlated with increased AR in the adjacent stroma. This, along with the CYP17 expression, suggests that androgens, in addition to being a source of estrogens, may be important in stimulating the stroma itself, acting in an autocrine fashion. Previous studies have implicated androgens in the pathogenesis of ovarian cancer ${ }^{40}$ and have reported that within the ovaries, the secretion rate of androgens is higher than that of estrogens. ${ }^{41}$ In addition, animal models have indicated that testosterone stimulates the growth in vivo of ovarian surface papillomas and cystadenomas. ${ }^{42}$

CYP19 (cytochrome P450 aromatase, an enzyme involved in the final step of estrogen synthesis, converting testosterone to estradiol ${ }^{17,38,43}$ ), was expressed in several tumors, however no significant findings were observed. Likewise, a significant correlation between CYP19 and ER in the neoplastic epithelium was not seen. However, there was a correlation with greater ER in the adjacent stroma itself, specifically in high-grade serous carcinoma, again suggesting a possible autocrine function.

$H S D 17 \beta 1$, an enzyme that converts low activity estrone to the more potent estradiol, ${ }^{38}$ was the least frequently expressed and no significant correlation 
was observed with ER expression in either the epithelium or in the stroma.

Overall, our results showed that ovarian stroma, particularly the stroma immediately adjacent to epithelium, was consistently immunoreactive for inhibin, calretinin and SF-1, CYP17, and AKR1C3, less frequently for $C Y P 19$, and rarely for $H S D 17 \beta 1$. Inhibin, calretinin and SF-1 identify hormonally active cells whereas the enzymes specifically indicate that these cells are the site of steroid hormone synthesis. The intense localization of these enzymes not only in the stroma surrounding the tumor but also within nests of tumor cells in contrast to the stroma distant from the tumors in the vast majority of ovarian neoplasms evaluated strongly suggests that there is an interaction between the tumors and the stroma. Further, steroid hormone receptors, including androgen receptor, were frequently expressed in the epithelium of the vast majority of tumors with the notable exception of mucinous tumors, therefore demonstrating their capacity to be stimulated by the hormones produced by the stroma. The absence of hormone receptors in the epithelium of mucinous tumors may be due to their not being derived from müllerian epithelium.

In endometriosis, activated ovarian stroma was also present adjacent to epithelium. Although greater composite scores for expression of markers of steroidogenesis and steroid enzymes were present in adjacent stroma in these lesions, the findings were not statistically different compared with distant stroma. The finding that hormone receptors were consistently expressed in endometriosis epithelium and adjacent stroma suggests that stroma may stimulate the epithelium in endometriosis as well.

Another interesting observation was the presence of activated ovarian stroma surrounding cortical inclusion cysts lined by tubal-type epithelium and the presence of hormone receptors in the epithelium albeit overall less than that of the ovarian tumors (Figure 6). We also evaluated ovarian surface epithelium and found minimal expression of SF-1, negligible inhibin and only rare expression of only AKR1C3 in the underlying stroma, with some expression of hormone receptors in the epithelium. Despite some immunoreactivity, the expression of markers of steroidogenesis and steroid enzymes was significantly less in the adjacent stroma surrounding cortical inclusion cysts and beneath the ovarian surface epithelium compared with the distant ovarian stroma. These findings suggest that unlike the tumors, benign epithelium does not lead to activation of the stroma.

In conclusion, this study provides morphologic and immunohistochemical evidence that tumors in the ovary activate the stroma to produce steroid hormones, most often androgens, and provides one possible explanation of why tumors thought to be derived from the fallopian tube and endometrium may grow preferentially in the ovary. Additional studies are needed to confirm whether the activated ovarian stroma surrounding neoplasms produces estrogens and androgens and, if so, whether their levels are sufficient to stimulate and support tumor growth. The potential interaction of the stroma and the ovarian carcinomas is highly provocative as it may open the door for novel approaches to treatment as the activated ovarian stroma may serve as a therapeutic target for anti-androgenic drugs.

\section{Acknowledgments}

We would like to acknowledge Dr Howard Zacur, The Theodore and Ingrid Baramky Professor of Reproductive Endocrinology, Director of the Division of Reproductive Endocrinology and Infertility at The Johns Hopkins Hospital, for his review of the manuscript and helpful constructive criticisms.

\section{Disclosure/conflict of interest}

The authors declare no conflict of interest.

\section{References}

1 Kurman RJ, Shih IeM. The origin and pathogenesis of epithelial ovarian cancer: a proposed unifying theory. Am J Surg Pathol 2010;34:433-443.

2 Kuhn E, Kurman RJ, Shih IM. Ovarian cancer is an imported disease: fact or fiction? Curr Obstet Gynecol Rep 2012;1:1-9.

3 Lim D, Oliva E. Precursors and pathogenesis of ovarian carcinoma. Pathology 2013;45:229-242.

4 Perets R, Wyant GA, Muto KW, et al. Transformation of the fallopian tube secretory epithelium leads to highgrade serous ovarian cancer in Brca;Tp53;Pten models. Cancer Cell 2013;24:751-765.

5 Lee Y, Miron A, Drapkin R, et al. A candidate precursor to serous carcinoma that originates in the distal fallopian tube. J Pathol 2007;211:26-35.

6 Crum CP, Drapkin R, Miron A, et al. The distal fallopian tube: a new model for pelvic serous carcinogenesis. Curr Opin Obstet Gynecol 2007;19:3-9.

7 Kindelberger DW, Lee Y, Miron A, et al. Intraepithelial carcinoma of the fimbria and pelvic serous carcinoma: evidence for a causal relationship. Am J Surg Pathol 2007;31:161-169.

8 Folkins AK, Jarboe EA, Roh MH, et al. Precursors to pelvic serous carcinoma and their clinical implications. Gynecol Oncol 2009;113:391-396.

9 Salvador S, Rempel A, Soslow RA, et al. Chromosomal instability in fallopian tube precursor lesions of serous carcinoma and frequent monoclonality of synchronous ovarian and fallopian tube mucosal serous carcinoma. Gynecol Oncol 2008;110:408-417.

10 Beral V, Gaitskell K, Hermon C, et al. Menopausal hormone use and ovarian cancer risk: individual participant meta-analysis of 52 epidemiological studies. Lancet 2015;385:1835-1842.

11 Wimalasena J, Dostal R, Meehan D. Gonadotropins, estradiol, and growth factors regulate epithelial ovarian cancer cell growth. Gynecol Oncol 1992;46:345-350. 
12 Chen C, Petitclerc E, Zhou $\mathrm{H}$, et al. Effect of reproductive hormones on ovarian epithelial tumors: II. Effect on angiogenic activity. Cancer Biol Ther 2002;1:307-312.

13 Shi WF, Bartlett JS. Estrogen plays a critical role in AAV2-mediated gene transfer in ovarian cancer. Acta Pharmacol Sin 2008;29:1440-1450.

14 Hua K, Feng W, Cao Q, et al. Estrogen and progestin regulate metastasis through the PI3K/AKT pathway in human ovarian cancer. Int J Oncol 2008;33:959-967.

15 Nourbakhsh M, Golestani A, Zahrai M, et al. Androgens stimulate telomerase expression, activity and phosphorylation in ovarian adenocarcinoma cells. Mol Cell Endocrinol 2010;330:10-16.

16 Elattar A, Warburton KG, Mukhopadhyay A, et al. Androgen receptor expression is a biological marker for androgen sensitivity in high grade serous epithelial ovarian cancer. Gynecol Oncol 2012;124:142-147.

17 Scully RE, Cohen RB. Oxidative-enzyme activity in normal and pathologic human ovaries. Obstet Gynecol 1964;24:667-681.

18 Kuhn E, Kurman RJ, Sehdev AS, et al. Ki-67 labeling index as an adjunct in the diagnosis of serous tubal intraepithelial carcinoma. Int J Gynecol Pathol 2012;31: 416-422.

19 Zhao C, Barner R, Vinh TN, et al. SF-1 is a diagnostically useful immunohistochemical marker and comparable to other sex cord-stromal tumor markers for the differential diagnosis of ovarian sertoli cell tumor. Int J Gynecol Pathol 2008;27:507-514.

20 Kato N, Hayasaka T, Takeda J, et al. Ovarian tumors with functioning stroma: a clinicopathologic study with special reference to serum estrogen level, stromal morphology, and aromatase expression. Int J Gynecol Pathol 2013;32:556-561.

21 Kurman RJ, Shih IeM. The dualistic model of ovarian carcinogenesis: revisited, revised, and expanded. Am J Pathol 2016;186:733-747.

22 Taylor J, McCluggage WG. Ovarian seromucinous carcinoma: report of a series of a newly categorized and uncommon neoplasm. Am J Surg Pathol 2015;39:983-992.

23 Maeda D, Shih IeM. Pathogenesis and the role of ARID1A mutation in endometriosis-related ovarian neoplasms. Adv Anat Pathol 2013;20:45-52.

24 Rutgers JL, Scully RE. Ovarian mullerian mucinous papillary cystadenomas of borderline malignancy. A clinicopathologic analysis. Cancer 1988;61:340-348.

$25 \mathrm{Wu} \mathrm{CH}$, Mao TL, Vang R, et al. Endocervical-type mucinous borderline tumors are related to endometrioid tumors based on mutation and loss of expression of ARID1A. Int J Gynecol Pathol 2012;31:297-303.

26 Kurman RJ, Shih IeM. Seromucinous tumors of the ovary. What's in a name? Int J Gynecol Pathol 2016;35:78-81.

27 Longacre TA, Bell DA, Malpica A, et al. Mucinous tumours In: Kurman RJ, Carcangui ML, Herrington S, Young RH (eds) WHO Classification of Tumours of Female Reproductive Organs. International Agency for Research on Cancer: Lyon, France, 2014, pp 25-28.

28 Ishikura H, Sasano H. Histopathologic and immunohistochemical study of steroidogenic cells in the stroma of ovarian tumors. Int J Gynecol Pathol 1998;17: 261-265.

29 Tokunaga H, Akahira J, Suzuki T, et al. Ovarian epithelial carcinoma with estrogen-producing stroma. Pathol Int 2007;57:285-290.

30 Hanley NA, Ikeda Y, Luo X, et al. Steroidogenic factor 1 (SF-1) is essential for ovarian development and function. Mol Cell Endocrinol 2000;163:27-32.

31 Ozisik G, Achermann JC, Jameson JL. The role of SF1 in adrenal and reproductive function: insight from naturally occurring mutations in humans. Mol Genet Metab 2002;76:85-91.

32 Ozisik G, Achermann JC, Meeks JJ et al. SF1 in the development of the adrenal gland and gonads. Horm Res 2003;59:94-98.

33 Sato Y, Suzuki T, Hidaka K, et al. Immunolocalization of nuclear transcription factors, DAX-1 and COUP-TF II, in the normal human ovary: correlation with adrenal 4 binding protein/steroidogenic factor-1 immunolocalization during the menstrual cycle. J Clin Endocrinol Metab 2003;88:3415-3420.

34 Mason AJ, Hayflick JS, Ling N, et al. Complementary DNA sequences of ovarian follicular fluid inhibin show precursor structure and homology with transforming growth factor-beta. Nature 1985;318: 659-663.

35 Findlay JK. An update on the roles of inhibin, activin, and follistatin as local regulators of folliculogenesis. Biol Reprod 1993;48:15-23.

36 Zheng W, Lu JJ, Luo F, et al. Tumor stroma as the main source of inhibin production in ovarian epithelial tumors. Am J Reprod Immunol 2000;44:104-113.

37 Deavers MT, Malpica A, Ordonez NG, et al. Ovarian steroid cell tumors: an immunohistochemical study including a comparison of calretinin with inhibin. Int J Gynecol Pathol 2003;22:162-167.

38 Hanukoglu I. Steroidogenic enzymes: structure, function, and role in regulation of steroid hormone biosynthesis. J Steroid Biochem Mol Biol 1992;43: 779-804.

39 Lin SX, Shi R, Qiu W, et al. Structural basis of the multispecificity demonstrated by 17beta-hydroxysteroid dehydrogenase types 1 and 5. Mol Cell Endocrinol 2006;248:38-46.

40 Risch HA. Hormonal etiology of epithelial ovarian cancer, with a hypothesis concerning the role of androgens and progesterone. J Natl Cancer Inst 1998;90:1774-1786.

41 O'Malley BW. Steroid hormones: metabolism and mechanism of action. In: Yen SSC (ed). Reproductive Endocrinology. Physiology, Patholophysiology and Clinical Management. 3rd edn Philadelphia, PA: Saunders. 1991;156-180.

42 Silva EG, Tornos C, Fritsche HA Jr, et al. The induction of benign epithelial neoplasms of the ovaries of guinea pigs by testosterone stimulation: a potential animal model. Mod Pathol 1997;10:879-883.

43 Song Z. Ovarian enzymatically active stromal cells can be a promoter of ovarian surface epithelial tumor. Med Hypotheses 2011;77:356-358. 